\title{
Laboratory simulation for the aqueous OH-oxidation of methyl vinyl ketone and methacrolein: significance to the in-cloud SOA production
}

\author{
X. Zhang, Z. M. Chen, and Y. Zhao \\ State Key Laboratory of Environmental Simulation and Pollution Control, College of Environmental Sciences and \\ Engineering, Peking University, Beijing 100871, China
}

Received: 12 May 2010 - Published in Atmos. Chem. Phys. Discuss.: 25 June 2010

Revised: 1 October 2010 - Accepted: 1 October 2010 - Published: 8 October 2010

\begin{abstract}
Increasing evidence suggests that secondary organic aerosol (SOA) is formed through aqueous phase reactions in atmospheric clouds. In the present study, the aqueous oxidation of methyl vinyl ketone (MVK) and methacrolein (MACR) via $\mathrm{OH}$ radical were investigated, with an emphasis on the composition and variation of small-molecular-weight organic products. In addition, high-molecular-weight compounds (HMWs) were found, interpreted as the ion abundance and time evolution. Our results provide, for the first time to our knowledge, experimental evidence that aqueous $\mathrm{OH}-$ oxidation of MVK contributes to SOA formation. Further, a mechanism primarily involving radical processes was proposed to gain a basic understanding of these two reactions. Based on the assumed mechanism, a kinetic model was developed for comparison with the experimental results. The model reproduced the observed profiles of first-generation intermediates, but failed to simulate the kinetics of most organic acids mainly due to the lack of chemical kinetics parameters for HMWs. A sensitivity analysis was performed in terms of the effect of stoichiometric coefficients for precursors on oxalic acid yields and the result indicates that additional pathways involving HMWs chemistry might play an important role in the formation of oxalic acid. We suggest that further study is needed for better understanding the behavior of multi-functional products and their contribution to the oxalic acid formation.
\end{abstract}

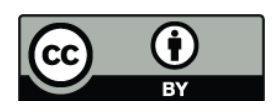

Correspondence to: Z. M. Chen (zmchen@pku.edu.cn)

\section{Introduction}

Atmospheric processes involving suspended water droplets in clouds play an important role in the production and removal of ambient fine particles (Blando and Turpin, 2000). Recently, interest in the potential formation of secondary organic aerosols (SOA) from cloud processing is growing. The hypothesis for the in-cloud SOA production is that the oxidation of reactive species in the interstitial space of clouds generates water soluble species. They dissolve into cloud droplets and undergo further oxidation, creating lowvolatility compounds. These compounds remain at least in part in the particle phase after droplet evaporation, leading to SOA (Kanakidou et al., 2005). This hypothesis has been supported by a number of laboratory studies, the results of which roughly followed two tracks. The first is the lowvolatility organic acid formation (Carlton et al., 2006, 2007, 2009; Altieri et al., 2008), which also provides an additional source of particle-phase oxalate observed in cloud-influenced air masses (Sorooshian et al., 2007). The second active track is the oligomer and humic-like substances (HULIS) production from the photooxidation of a series of low-molecularweight species, including pyruvic acid (Altieri et al., 2006; Guzman et al., 2006), glyoxal (Carlton et al., 2007; Volkamer et al., 2009), methylglyoxal (Altieri et al., 2008), and glycolaldehyde (Perri et al., 2009). In light of the laboratory evidence, recent models predicted a substantial increase of SOA production when aqueous SOA formation pathways were incorporated (Lim et al., 2005; Chen et al., 2007; Carlton et al., 2007; Ervens et al., 2008). However, the mechanism with respect to the aqueous chemistry has not been completely understood and SOA precursors included in current models that represent cloud processing are limited. 
Methacrolein (MACR) and methyl vinyl ketone (MVK), as two major first-generation products in the oxidation of isoprene, are of great interest due to their large global abundance (Montzka et al., 1993; Griffin et al., 1999; Simpson et al., 1999) and high reactivity (Gierczak et al., 1997; Chen et al., 2008b). The atmospheric transformation of these two carbonyls has received considerable studies, mainly including determining their gas-phase reaction products (Tuazon and Atkinson, 1989, 1990; Aschmann et al., 1996; Orlando et al., 1999), measuring aerosol growth from their photooxidation (Kroll et al., 2006; Ng et al., 2006), elucidating reaction pathways in terms of SOA formation (Kroll et al., 2005; Surratt et al., 2006; Szmigielski et al. 2007), and investigating their uptake kinetics onto particles (Nozière et al., 2006; Chen et al., 2008a; Zhao et al., 2010). Chamber experiments have demonstrated that MACR is an important intermediate in SOA formation whereas MVK was found to produce no SOA (Kroll et al., 2006; Surratt et al., 2006). However, the detailed mechanism of SOA formation from these two species via their aqueous oxidation remains uncertain. Tropospheric lifetimes $\left(\tau_{\mathrm{OH}}\right)$ of MACR and MVK are estimated to be 6-10 h (Atkinson and Arey, 2003), thus enabling them to have great concentrations at higher altitudes (Henze et al., 2006) or encounter a cloud formation process in the air above boreal forests. Indeed, both of them have been observed in cloud droplets with high concentrations (i.e. $<\mathrm{DL} \sim 0.5 \mu \mathrm{M}$ for MACR and 0.02 0.2 $\mu \mathrm{M}$ for MVK, van Pinxteren et al., 2005), highlighting the importance of their aqueous photochemistry in SOA formation. To our knowledge, Claeys et al. (2004) put forth a possible route to SOA formation from aqueous-phase acid-catalyzed oxidation of MACR by hydrogen peroxide. Liu et al. (2009) studied the photooxidation of MACR in the aqueous phase under simulated cloud droplet conditions. They proposed that the radical chemistry could explain the products observed from $\mathrm{OH}$-oxidation of MACR. El Haddad et al. (2009) investigated the fate of MACR in cloud evapo-condensation cycles, estimating that SOA yield ranged from 2 to $12 \%$. Nozière et al. (2010) reported that sulfate salts could play important roles on the transformation of MACR/MVK to organosulfates in wet aerosols, when exposed to light. Up to date, the aqueous oxidation of MVK via $\mathrm{OH}$ radicals has not been experimentally studied.

Here we simulate experimentally the aqueous $\mathrm{OH}$-initiated oxidation of MACR and MVK at $\mathrm{pH}$ and temperature values typical of atmospheric clouds. Small products were well characterized and evidence of high-molecular-weight compounds (HMWs) formation was presented. The product analysis provides useful information for elucidating the mechanism underlying aqueous reactions of MACR/MVK with $\mathrm{OH}$ radical. Based on the proposed mechanism, a detailed kinetic model was developed to better understand the in-cloud chemistry of these two carbonyls.

\section{Experimental}

\subsection{Reagents and materials}

The solutions were prepared using MACR (Alfa Aesar, 95+\%); MVK (Avocado, 95+\%); $\mathrm{H}_{2} \mathrm{O}_{2}$ (Sigma, 50\% water solution); and $\mathrm{H}_{2} \mathrm{SO}_{4}$ (Beijing Chemical Plant, 98\%) diluted in ultrapure water (Milli-Q). The initial concentrations of MACR, MVK, and $\mathrm{H}_{2} \mathrm{O}_{2}$ in the reactor were $0.2,0.2$, and $2 \mathrm{mM}$, respectively, in HPLC-UV and IC analysis. These values, which were $\sim$ two orders of magnitude higher than those in atmospheric cloud droplets, were used to better characterize the possible products formed. The initial concentrations of reactants are ten times higher in HPLC-MS analysis for better characterizing the high molecular weight ions formed. The source and purity of each authentic standard for verifying possible products are: formaldehyde (Riedel-delaen, $36.5 \%$ solution), glyoxal (Sigma, 40\% solution), methylglyoxal (Avocado, 40\% solution), formic acid (Alfa Aesar, 97\%), acetic acid (Alfa Aesar, 99.9985\%), pyruvic acid (Avocado, 98\%), oxalic acid (Alfa Aesar, anhydrous, 98\%), and malonic acid (Alfa Aesar, 99.5+\%).

\subsection{Apparatus}

The experiment was carried out in a $2.1 \mathrm{~L}$ quartz reactor. The OH radical source is the photolysis of hydrogen peroxide. The irradiation was performed by a Xenon arc lamp (300W, Perkin Elmer), which was mounted above the reactor. Temperature was controlled by circulating water in the jacket surrounding the reactor. The volume of the aqueous solution was $2 \mathrm{~L}$. A $0.1 \mathrm{~L}$ gas space was left over the liquid level. Because of the existence of the top gas space, the upper limits for the loss of aqueous MACR and MVK were estimated to be $\sim 0.07 \%$ and $\sim 0.01 \%$, respectively, based on their Henry constants (i.e. $6.5 \mathrm{M} \mathrm{atm}^{-1}$ for MACR and $41 \mathrm{M} \mathrm{atm}^{-1}$ for MVK at $298 \mathrm{~K}$ ) (Iraci et al., 1999). Therefore, the interference of gas-phase reactions can be eliminated.

\subsection{Procedures}

The aqueous reactions were carried out as close as possible to the conditions of atmospheric cloud droplets, namely, $T=$ $283 \mathrm{~K}$ and $\mathrm{pH}=4$ (van Pinxteren et al., 2005, electronic supplementary material). Before the irradiation, reagents were introduced into the reactor and the aqueous mixture was magnetically stirred for $15 \mathrm{~min}$. Reactants and products were pumped out of the reactor and analyzed periodically over the course of an experiment.

\subsection{Control experiments}

To verify that the observed products resulted from the aqueous $\mathrm{OH}$-oxidation, five control experiments were conducted: (1) $\mathrm{H}_{2} \mathrm{O}_{2}(11 \mu \mathrm{M})+$ MACR $(4.6 \mu \mathrm{M})$; (2) $\mathrm{H}_{2} \mathrm{O}_{2}(2 \mathrm{mM})$ + MVK $(0.2 \mathrm{mM})$; (3) $\mathrm{H}_{2} \mathrm{O}_{2}(2 \mathrm{mM})+\mathrm{UV}$; (4) MACR 


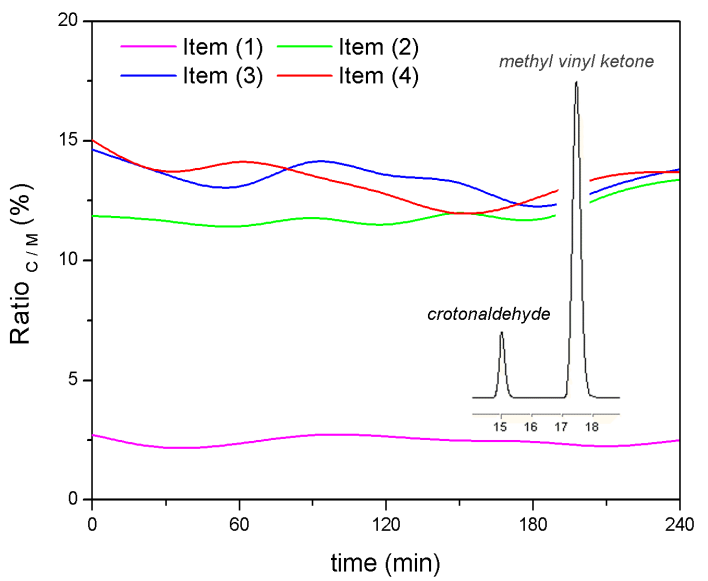

Fig. 1. Transformation of MVK in water solution. Item (1): $0.2 \mathrm{mM}$ MVK in acetonitrile ( $\mathrm{pH}=7)$; Item (2): $0.2 \mathrm{mM}$ MVK in ultrapure water ( $\mathrm{pH}=7$ ); Item (3): $0.2 \mathrm{mM} \mathrm{MVK}+2 \mathrm{mM} \mathrm{H}_{2} \mathrm{O}_{2}$ in ultrapure water ( $\mathrm{pH}=7)$; and Item (4): $0.2 \mathrm{mM} \mathrm{MVK}+2 \mathrm{mM} \mathrm{H}_{2} \mathrm{O}_{2}$ in ultrapure water $(\mathrm{pH}=4)$. (The inset figure is the HPLC-UV spectra of MVK dissolved in ultrapure water).

$(0.2 \mathrm{mM})+\mathrm{UV}$; and (5) MVK $(0.2 \mathrm{mM})+\mathrm{UV}$. In our previous study, we have confirmed that $\mathrm{H}_{2} \mathrm{O}_{2}$ has no significant effect on the transformation of MACR in darkness under our experimental condition (Zhang et al., 2009), likewise the fate of MVK, see items (3) and (4) in Fig. 1. The continuous photolysis of $\mathrm{H}_{2} \mathrm{O}_{2}$, which was extensively studied before, generates $\mathrm{OH}$ radicals directly. Figure $\mathrm{S} 1$ in the supplementary material shows that the model reproduces the time evolution of $2 \mathrm{mM} \mathrm{H}_{2} \mathrm{O}_{2}$ solution under photolysis. Note that the degradation rate of $\mathrm{H}_{2} \mathrm{O}_{2}$ is slightly lower than those together with MACR/MVK, indicating the competition for $\mathrm{OH}$ radicals between MACR/MVK and $\mathrm{H}_{2} \mathrm{O}_{2}$. As for the UVirradiation case, the decay of MACR/MVK due to the photolysis is far slower than that by OH-oxidation, see Fig. S2 in the supplementary material, so MACR/MVK was consumed primarily by means of $\mathrm{OH}$ radicals not by direct photolysis.

To verify the stability of known products in hydrogen peroxide, two mixed standards were prepared: (1) formaldehyde $(0.1 \mathrm{mM})+$ methylglyoxal $(0.1 \mathrm{mM})+$ glyoxal $(0.1 \mathrm{mM})$ $+\mathrm{H}_{2} \mathrm{O}_{2}(2 \mathrm{mM})+\mathrm{H}_{2} \mathrm{SO}_{4}(0.05 \mathrm{mM})$; and (2) formic acid $(0.1 \mathrm{mM})+$ acetic acid $(0.1 \mathrm{mM})+$ pyruvic acid $(0.1 \mathrm{mM})+$ oxalic acid $(0.1 \mathrm{mM})+\mathrm{H}_{2} \mathrm{O}_{2}(2 \mathrm{mM})+\mathrm{H}_{2} \mathrm{SO}_{4}(0.05 \mathrm{mM})$. Samples were kept in $283 \mathrm{~K}$ in darkness until analysis by HPLC-UV or IC. The results show that the effect of $\mathrm{H}_{2} \mathrm{O}_{2}$ on the stability of carbonyls is insignificant, see Fig. S3 in the supplementary material. However, rapid pyruvic acid loss occurs within $10 \mathrm{~min}$ and in the meantime, acetic acid concentration substantially increases, as shown in Fig. S4 in the supplementary material. The rapid transformation of pyruvic acid to acetic acid in $\mathrm{H}_{2} \mathrm{O}_{2}$ solution, which is consistent with previous studies (Carlton et al., 2006), can explain the unexpected loss of pyruvic acid over the course of $\mathrm{OH}$ oxidation.

\subsection{Product analysis}

In the present study, the carbonyl compounds were analyzed by determining their derivatives of 2, 4dinitrophenyhydrazine (DNPH) using high-performance liquid chromatography (HPLC) instrument (Agilent 1100, USA) equipped with an ultraviolet detector. The peroxides were determined on the basis of fluorescent analysis by HPLC instrument (Agilent 1100, USA) with postcolumn derivation, involving the hemin-catalyzed oxidation of peroxides to a fluorescent derivative using hydroxyphenylacetic acid (Hua et al., 2008). The organic acids were analyzed using ion chromatography (DIONEX 2650, USA) equipped with an ED50 conductivity detector. An AS11 column $(4 \mathrm{~mm})$ with an AG11-HC $(4 \times 50 \mathrm{mM})$ guard column and an Anion Trap column (ATC-3, $9 \times 24 \mathrm{~mm}$, for $4 \mathrm{mM}$ ) were used for anion detection. The sampling volume was $100 \mathrm{~mL}$, and the eluting solution was $0.4-6 \mathrm{mM} \mathrm{NaOH}$ (gradient) with a flow rate of $1.2 \mathrm{~mL} / \mathrm{min}$. The detection limits of carbonyl compounds in ultrapure water solution can be found in our previous work (Wang et al., 2009); the detection limit of hydrogen peroxide in ultrapure water solution is $0.02 \mu \mathrm{M}$; the detection limits of formic, acetic, pyruvic, oxalic, and malonic acid in the ultrapure water solution are $0.08,0.1,0.5,0.04$, and $0.4 \mu \mathrm{M}$, respectively. In addition, a HP 1100 LC-MS Trap SL System (Agilent, USA) consisting of a series 1100 HPLC and an ion trap mass spectrometer equipped with electro-spray interface (ESI) was used to determine the HMWs. The chromatographic isocratic separations were performed on a LC column (Agilent ZORBAX SB-C $18,2.1 \times 150 \mathrm{~mm}, 5 \mu \mathrm{m})$ at $26^{\circ} \mathrm{C}$, the mobilephase was methanol/water mixture $(40 / 60, \mathrm{v} / \mathrm{v})$ at a flow rate of $0.25 \mathrm{~mL} / \mathrm{min}$. The electro-spray ionization was performed in the positive/negative ion mode under optimum conditions as follows: capillary voltage $3500 \mathrm{~V}$, nebulizer pressure $35.0 \mathrm{psi}$, dry gas flow rate $8.0 \mathrm{~L} \mathrm{~min}^{-1}$ and dry gas temperature $330^{\circ} \mathrm{C}$. Full scan mode was used to acquire the MS spectra of the HMWs with a scan range of $\mathrm{m} / \mathrm{z}$ from 35 to 300 .

\subsection{Modeling methodology}

A box model was performed using the aqueous $\mathrm{OH}$-oxidation mechanism elucidated in Section 3.3. This specific mechanism, which is on the basis of CAPRAM 3.0 developed by Herrmann et al. (2000) and updated by Herrmann et al. (2005), includes 64 aqueous reactions involving MACR/MVK and their small products, in addition to 2 photolysis reaction, as listed in Table $\mathrm{S} 1$ that can be found in the supplementary material. The initial MACR/MVK, $\mathrm{H}_{2} \mathrm{O}_{2}$ and $\mathrm{O}_{2}$ concentrations input were $0.2,2$, and $0.36 \mathrm{mM}$, respectively, representing those used in the experiments. The simulation was carried out on a 10-min basis and preceded for $7 \mathrm{~h}$. Modeled $\mathrm{OH}$ radical concentrations over the course of experiments were on average $1.5 \times 10^{-12}-2.0 \times 10^{-12} \mathrm{M}$ 
(Fig. S5 of the supplementary material), which were comparable with Tan et al. (2009).

\section{Results and discussion}

\subsection{Transformation of MVK}

As shown in Fig. 1, two peaks were found in the liquid chromatogram of MVK-DNPH derivative, indicating that in addition to MVK, another carbonyl coexisted in the experiment elute. This unknown carbonyl has been identified as crotonaldehyde, an isomeric compound of MVK (Wang et al., 2009). In order to avoid the analytical artifacts, four sets of solutions were prepared in darkness: (1) $0.2 \mathrm{mM}$ MVK in acetonitrile $(\mathrm{pH}=7)$; (2) $0.2 \mathrm{mM} \mathrm{MVK}$ in ultrapure water $(\mathrm{pH}=7)$; (3) $0.2 \mathrm{mM} \mathrm{MVK}+2 \mathrm{mM} \mathrm{H}_{2} \mathrm{O}_{2}$ in ultrapure water ( $\mathrm{pH}=7)$; and (4) $0.2 \mathrm{mM} \mathrm{MVK}+2 \mathrm{mM} \mathrm{H}_{2} \mathrm{O}_{2}$ in ultrapure water $(\mathrm{pH}=4)$. The temporal profile of solution (1), see Fig. 1, shows that the amount of MVK that transformed to crotonaldehyde in acetonitrile is to be minus, indicating that the observed transformation did not result from the analytical procedure. On the other hand, approximately one seventh of MVK dissolved in water turned into crotonaldehyde regardless of whether $\mathrm{H}_{2} \mathrm{O}_{2}$ or sulfuric acid was added, suggesting the potentially important role of water in inducing this transformation. Based on the generic hydration that has been studied previously (Nozière et al., 2006), the hydrolysis of MVK is proposed as follows (R1).

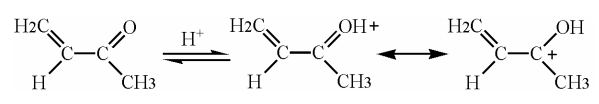

The subsequent formed carbonium ion is an important intermediate, through which the skeletal rearrangement are known to occur under certain conditions. Mechanisms for rearrangements of aliphatic ketones with sulfuric acid catalysis mainly involve the shift of conjugate acid hydroxyl group to an adjacent carbon atom (Barton et al., 1952), the shift of the carbonyl oxygen to an adjacent carbon atom (Zook et al., 1955), and the alkyl group shift (Rothrock and Fry, 1958). Application of the above mechanisms to MVK transformation leads to the prediction that the methyl group would exchange with a hydrogen atom of the vinyl group. However, it is impossible to exclude other pathways resulting in the rearrangement of MVK in the absence of catalysis. Further study is needed to elucidate mechanisms for the transformation of MVK to crotonaldehyde.

\subsection{Identification of low-molecular-weight products}

Products identified chromatographically in the OH-oxidation of MACR are formaldehyde (FA), methylglyoxal (MG), formic acid (FOA), acetic acid (AA), pyruvic acid (PA), and oxalic acid (OA). These observations are generally consistent with Liu et al. (2009), in which FA, MG, PA, and OA
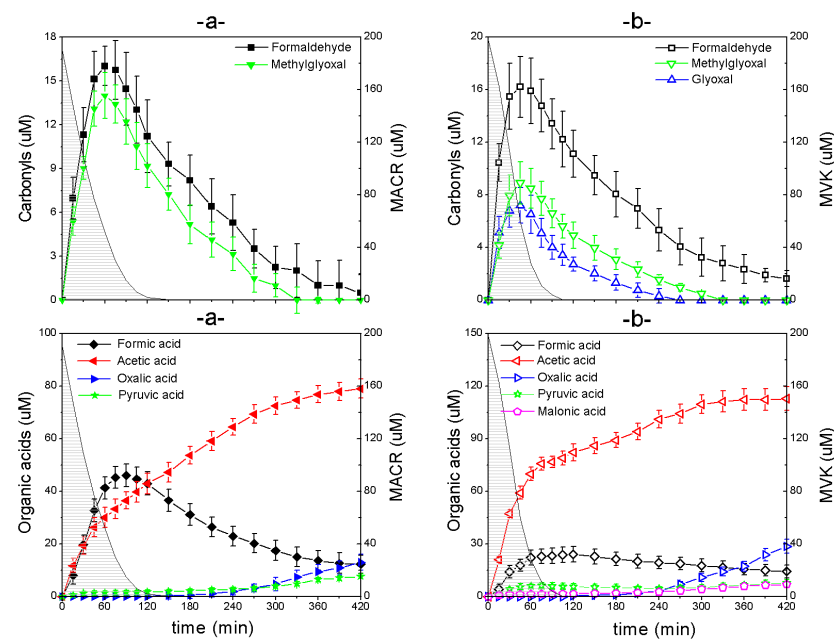

Fig. 2. Temporal concentration profiles of reactants and products in the aqueous OH-oxidation of (a) MACR, and (b) MVK $(283 \mathrm{~K}$, $\mathrm{pH}=4.0$ ).

were identified as well. In addition to these products, glyoxal (GL) and malonic acid (MA) are detected in the MVK-OH reaction system. It is not surprising for the oxalic acid formation in view of previous laboratory and model results, which confirmed that the aqueous phase oxidation of pyruvic acid, glyoxal, and methylglyoxal produced oxalic acid (Lim et al., 2005; Carlton et al., 2007; Altieri et al., 2008). The detection of malonic acid is less expected, although this observation is in agreement with a recent study. Perri et al. (2009) reported that malonic acid was a product of the $\mathrm{OH}$-oxidation of glycolaldehyde, which can be derived from the MVK-OH reaction mechanism proposed in Sect. 3.4. A pattern of kinetic curves for the aqueous oxidation of MACR via $\mathrm{OH}$ radical at pH 4 and $283 \mathrm{~K}$ is shown in Fig. 2a. Once the irradiation begins, MACR concentration decreases and various products form immediately. Based on the shape of growth curves, all the products can be classified into two different groups. One group includes formaldehyde, methylglyoxal and formic acid. Their concentrations are observed to decrease rapidly once MACR is depleted. On the contrary, concentrations of acetic acid, pyruvic acid, and oxalic acid continue to increase or reach a plateau even after MACR disappearance, indicating that reactions other than the initial MACR oxidation can give these compounds as well. Similar results for the MVK$\mathrm{OH}$ reaction are shown in Fig. $2 \mathrm{~b}$.

\subsection{Evidence for HMWs formation}

In addition to the small products, we also observed some compounds that are of a higher molecular weight than reactants. These compounds were not detected in a standard mixture including MACR, MVK, FA, GL, MG, FOA, AA, $\mathrm{PA}, \mathrm{OA}$, and MA, suggesting they are not artifacts during analytical procedures. The HPLC-MS spectra for selected 


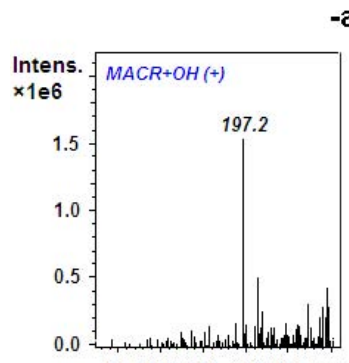

$-\mathrm{a}-$

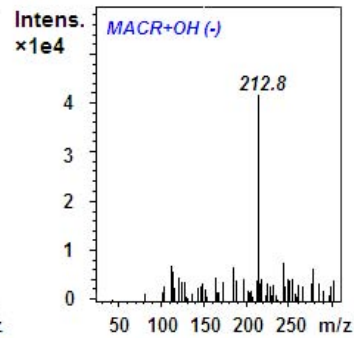

$\begin{array}{llllll}50 & 100 & 150 & 200 & 250 & \mathrm{~m} / \mathrm{z}\end{array}$
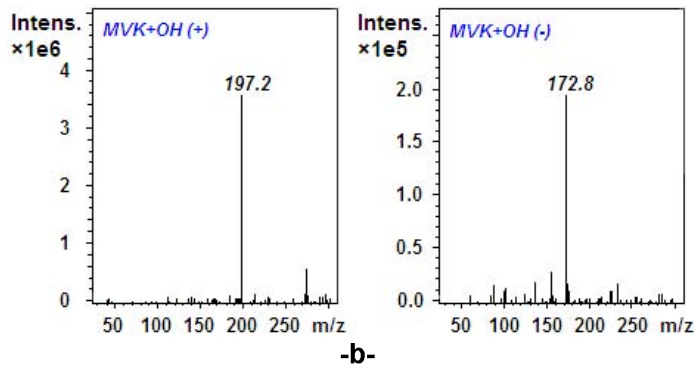

$\rightarrow \mathrm{m} / \mathrm{z}_{\mathrm{MAC}} 212.8-\rightarrow \mathrm{m} / \mathrm{z}_{\mathrm{MAC}} 258.8-\rightarrow \mathrm{m} / \mathrm{z}_{\mathrm{MAC}} 213.1+\mathrm{m} / \mathrm{z}_{\mathrm{MAC}} 273.1+\rightarrow \mathrm{m} / \mathrm{z}_{\mathrm{MAC}} 197.2+$
$\rightarrow \mathrm{m} / \mathrm{z}_{\mathrm{MVK}} 152.9-\rightarrow \mathrm{m} / \mathrm{z}_{\mathrm{MVK}} 170.0-\rightarrow-\mathrm{m} / \mathrm{z}_{\mathrm{MVK}} 213.2+\rightarrow \mathrm{m} / \mathrm{z}_{\mathrm{MVK}} 172.8-\rightarrow-\mathrm{m} / \mathrm{z}_{\mathrm{MVK}} 197.2+$

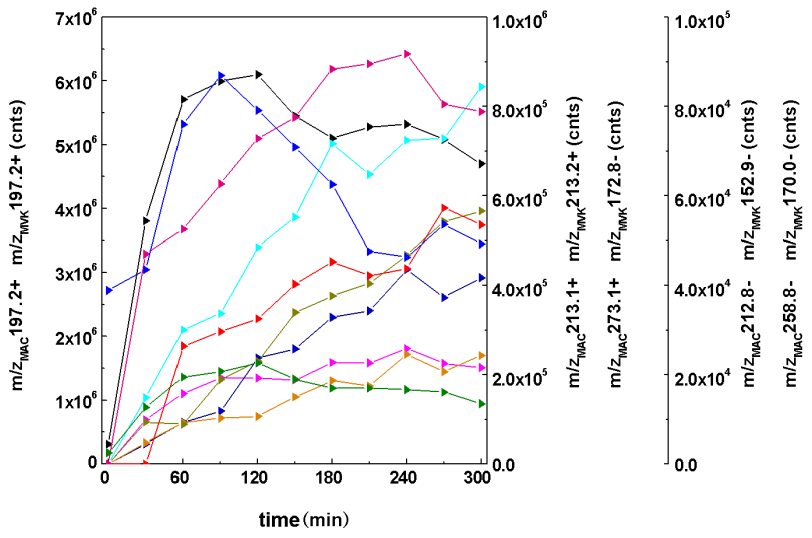

Fig. 3. Characteristics of high-molecular-weight ions (HMWs): (a) Selected HPLC-MS spectra of HMWs (The retention time of HMWs formed from MACR-OH reactions in positive and negative mode is $\sim 3-5$ and $\sim 2-4$ min, respectively. The retention time of HMWs formed from $\mathrm{MVK}-\mathrm{OH}$ reactions in positive and negative mode is $\sim 3-5$ and $\sim 2-4$ min, respectively.); (b) Evolution of selected HMWs from MACR/MVK-OH reactions.

high-molecular-weight ions in both positive and negative modes are shown in Fig. 3a. Most ions are distributed in the $\mathrm{m} / \mathrm{z}$ range of $150-300$. The time series of dominating HMWs are shown in Fig. 3b. The concentrations of HMWs increase rapidly in the beginning, and then, reach a plateau or decrease after $4 \mathrm{~h}$ reactions, indicating that they are sensitive to the photooxidation. This study provides evidence that the aqueous MACR/MVK oxidation produces HMWs. It should be noted the initial MACR/MVK concentration of $2 \mathrm{mM}$ used in the HPLC-MS analysis is much higher than that can be expected in cloud droplets. Tan et al. (2009) have revealed a strong dependence of the oligomer formation on the ini- tial precursor concentration in the aqueous $\mathrm{OH}$-oxidation of glyoxal. The glyoxal HMW production from the MVK-OH reaction, in which glyoxal is formed with a high yield as reported in our experiments, might need to consider this concentration effect.

\subsection{Mechanisms}

Mechanisms specific to the aqueous $\mathrm{OH}$-initiated oxidation of reactive species mainly include acid catalyzed chemical processes and radical chemistry. Altieri et al. (2008) proposed an acid catalyzed esterification pathway to explain the oligomer formation from reactions of methylglyoxal with $\mathrm{OH}$. Liu et al. (2009) proposed that the radical chemistry contribute to the products from the $\mathrm{OH}$-oxidation of MACR. More recently, the radical reaction mechanism has been employed to explain the organosulfates formation from aqueous reactions of sulfate radicals and organic compounds in the presence of light (Nozière et al., 2010; Perri et al., 2010). In this study, we suggest that the observed small products primarily result from free radical processes, see schemes in Figs. 4 and 5.

\subsubsection{MACR-OH}

The first step of MACR-OH reaction invariably includes terminal and central $\mathrm{OH}$ addition, and the aldehydic hydrogen atom abstraction by $\mathrm{OH}$. The electrophilic addition of $\mathrm{OH}$ produces two carbon-centered hydroxyl-containing radicals, followed by a sequence of rapid reaction with dissolved $\mathrm{O}_{2}$. The peroxyl radicals $\left(\mathrm{RO}_{2}\right)$ react primarily with $\mathrm{NO}, \mathrm{HO}_{2}$, $\mathrm{NO}_{3}$, and other $\mathrm{RO}_{2}$ in the atmosphere (Finlayson-Pitts and Pitts, 2000), while the self-reaction of $\mathrm{RO}_{2}$ become dominant in the aqueous phase. In principle, one expects a tetroxide structure (ROOOOR)* to be formed, which would decompose by four pathways, see Reaction (R2). This process has been extensively studied by von Sonntag and Schuchman (1997). The $\mathrm{R}_{1} \mathrm{R}_{2} \mathrm{CHO}$ radical formed via the second channel of Reaction (R2) is an important intermediate, and its dominating fate in the aqueous phase is the scission of $\mathrm{C}-\mathrm{C}$ bond, producing the observed formaldehyde, methylglyoxal, acetic acid, together with some free radicals. These radicals could be the origin of formic acid. Oxalic acid and pyruvic acid are mainly from the further oxidation of first generation products.

$$
\begin{aligned}
& \mathrm{R}_{1} \mathrm{R}_{2} \mathrm{CHOO}-\mathrm{OOCHR}_{1} \mathrm{R}_{2} \rightarrow \mathrm{R}_{1} \mathrm{R}_{2} \mathrm{C}=\mathrm{O} \\
& +\mathrm{R}_{1} \mathrm{R}_{2} \mathrm{CHOH}+\mathrm{O}_{2} \\
& \mathrm{R}_{1} \mathrm{R}_{2} \mathrm{CHOO}-\mathrm{OOCHR}_{1} \mathrm{R}_{2} \rightarrow 2 \mathrm{R}_{1} \mathrm{R}_{2} \mathrm{CHO} \cdot+\mathrm{O}_{2}
\end{aligned}
$$




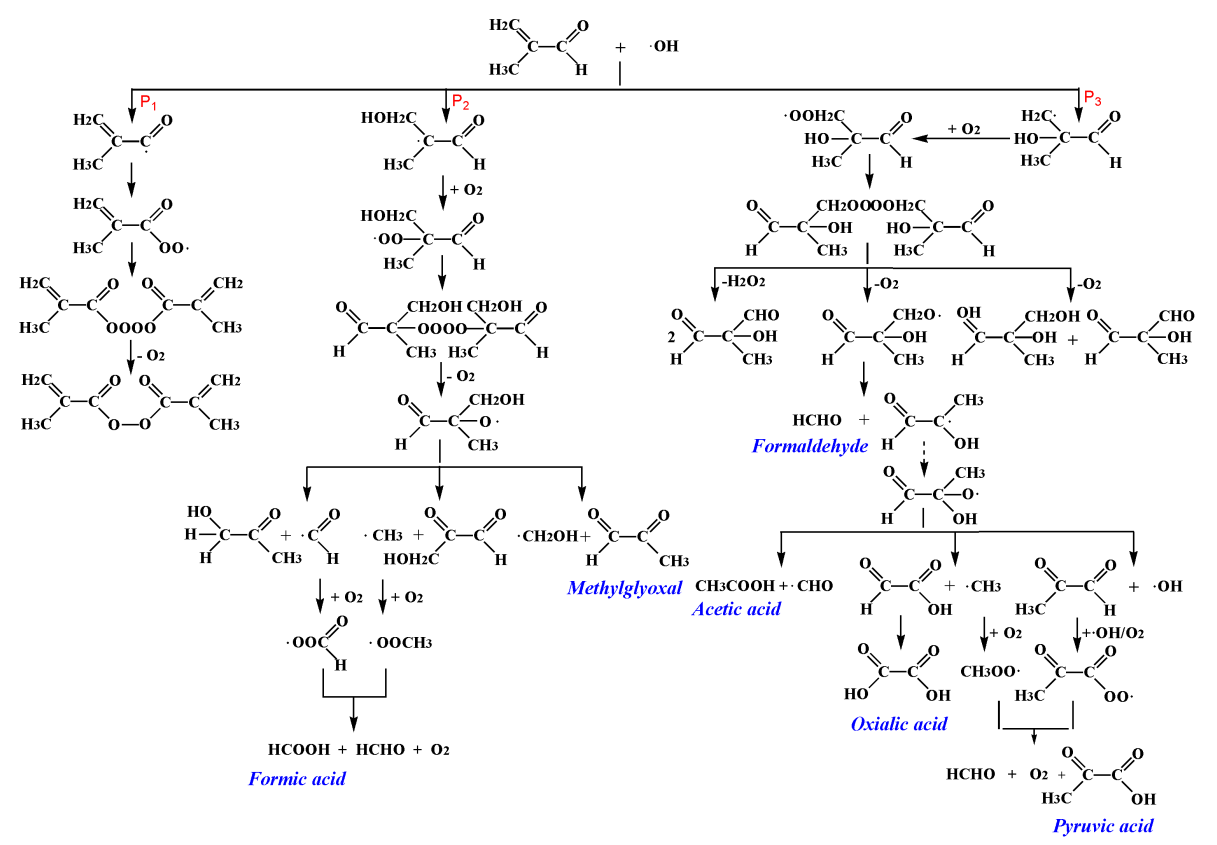

Fig. 4. Scheme for the tentatively proposed reaction pathways leading to the observed products from the MACR-OH reaction.

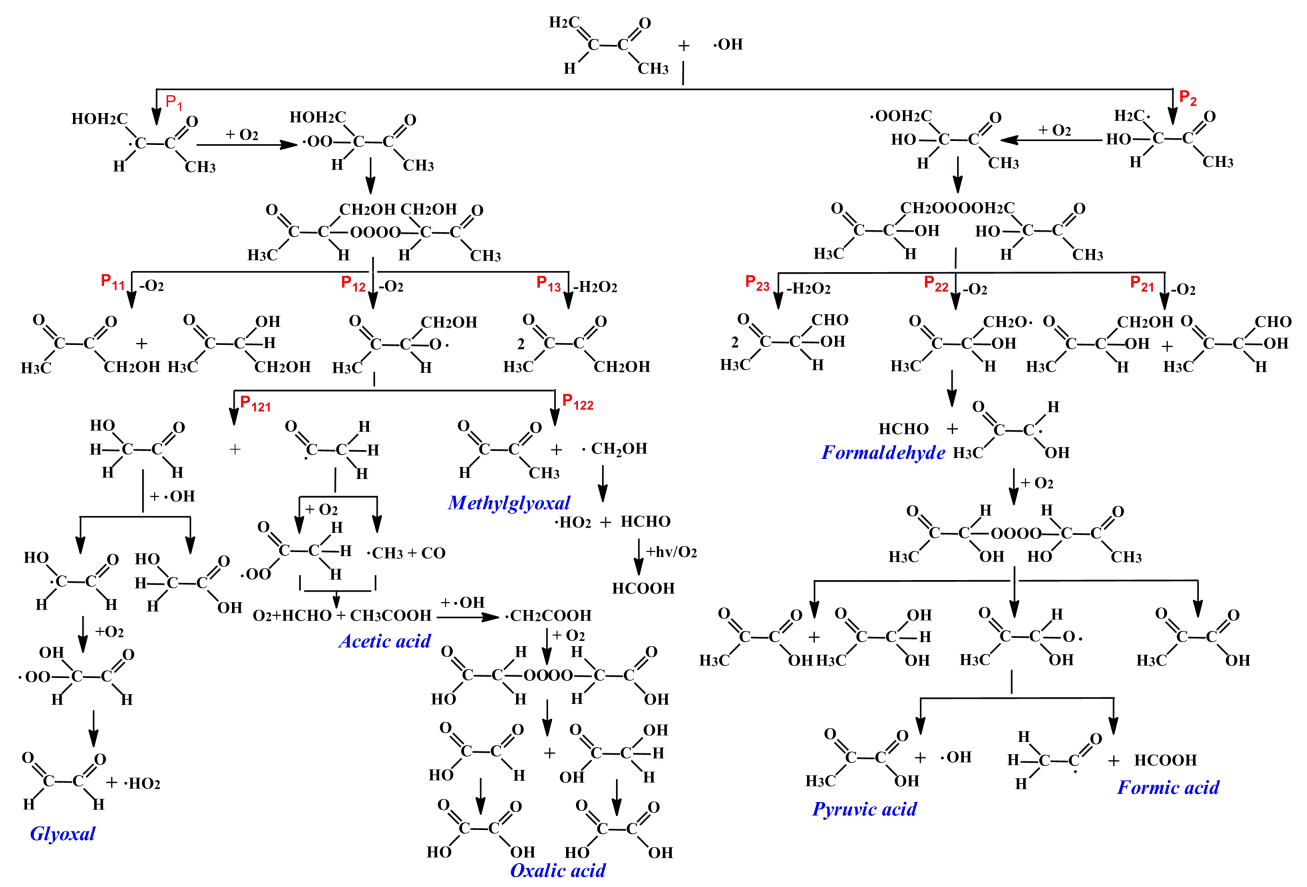

Fig. 5. Scheme for the tentatively proposed reaction pathways leading to the observed products from the MVK-OH reaction.

\subsubsection{MVK-OH}

In analogy to MACR, OH attacks MVK at the central and terminal carbon atoms of the double bond (reaction pathways denoted P1 and P2) to form two carbon-centered hydroxylcontaining radicals, which are then oxidized by $\mathrm{O}_{2}$ to pro- duce $\mathrm{RO}_{2}$ radicals. As discussed earlier, in a water cage, the self-reaction of $\mathrm{RO}_{2}$ radicals occurs, giving a tetroxide structure, which will decompose via four pathways, see Reaction (R2). Here we focus on the RO radical formation channel, namely, P12 and P22. 

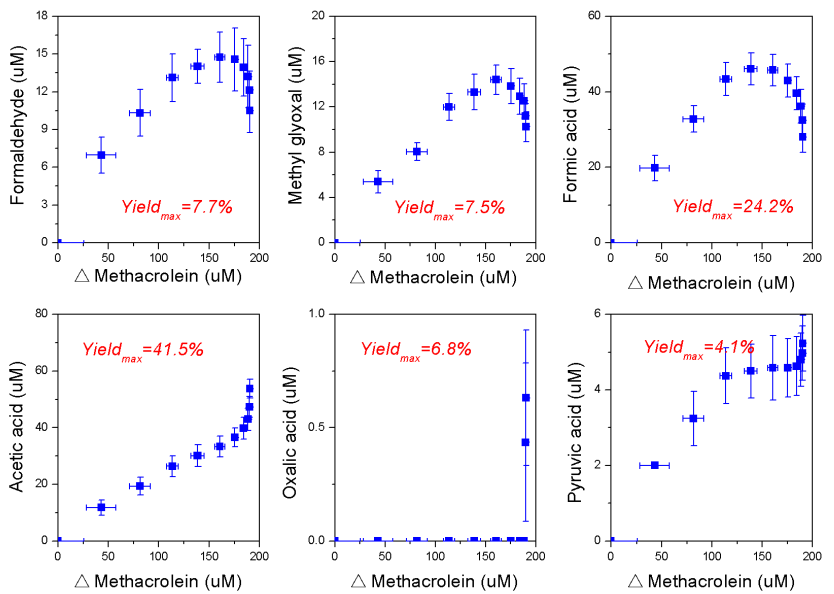

Fig. 6. Yields of low-molecular-weight products from the $\mathrm{OH}-$ oxidation of MACR.

For pathway P12, two types of RO radical decomposition are proposed, creating glycolaldehyde (P121) and methylglyoxal (P122), respectively. Glycolaldehyde contains a hydroxyl group adjacent which the abstraction of $\mathrm{H}$ atom by $\mathrm{OH}$ radical is more likely to occur, followed by a rapid $\mathrm{O}_{2}$ addition. The resulting $\mathrm{RO}_{2}$ radical, undergoing the elimination of $\mathrm{HO}_{2}$, yields glyoxal. The oxidation of glycolaldehyde also leads to glycolic acid. As mentioned earlier, malonic acid formation from the $\mathrm{OH}$-oxidation of glycolaldehyde has been reported, thus providing support that the observed malonic acid in our MVK-OH reaction system is reasonable. We assume that the combination of free radicals can probably give an explanation (Reaction R3). Accompanying glycolaldehyde, $\mathrm{CH}_{3} \mathrm{CO}$ radical is produced, and its further oxidation leads to acetic acid and subsequently, oxalic acid. As for methylglyoxal, its degradation initiates via the abstraction of aldehydic $\mathrm{H}$-atom by $\mathrm{OH}$ radical, producing pyruvic acid. Lim et al. (2005) proposed that a part of methylglyoxal contributed to the oxalic acid formation via glyoxylic acid, while the current mechanism did not include this route. Pathway P22 mainly results in formaldehyde, formic acid, and pyruvic acid, via similar pathways as P12.

$$
\begin{aligned}
& \cdot \mathrm{CH}_{2} \mathrm{OH}+\cdot \mathrm{CH}_{2} \mathrm{COOH} \rightarrow \mathrm{CH}_{2} \mathrm{OHCH}_{2} \mathrm{COOH} \stackrel{\mathrm{OH}}{\longrightarrow} \\
& \mathrm{CHOCH}_{2} \mathrm{COOH} \stackrel{\mathrm{OH}}{\longrightarrow} \mathrm{COOHCH} \mathrm{COOH}_{2} \mathrm{COOH}
\end{aligned}
$$

\subsection{Product yields}

A series of experiments for the aqueous $\mathrm{OH}$-oxidation of MACR/MVK were carried out at two controlled $\mathrm{pH}$ values $(\mathrm{pH}=4.0$ and 7.0). It turns out that the acidity has no significant effect on the molar yields of small products. Here the molar yield is defined as the ratio of the production molar amount of a product versus the consumption molar amount of a reactant (MACR/MVK). As shown in Fig. 6, the primary
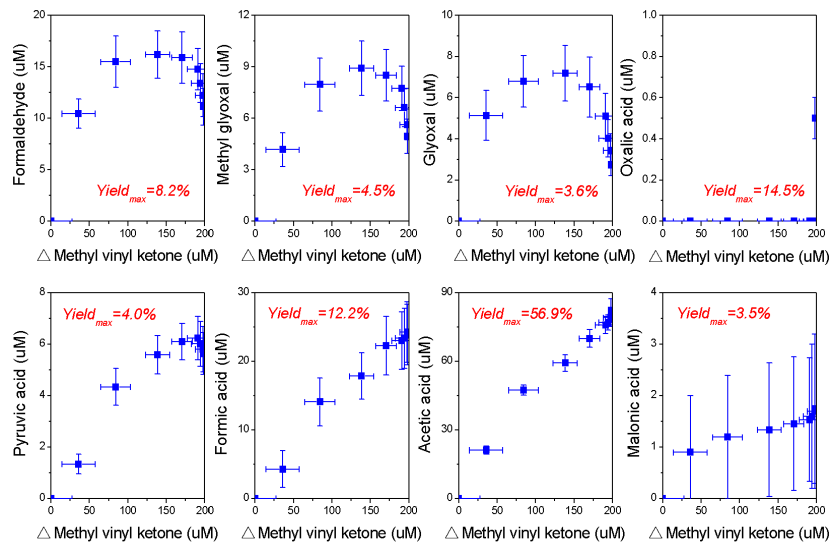

Fig. 7. Yields of low-molecular-weight products from the $\mathrm{OH}$ oxidation of MVK.

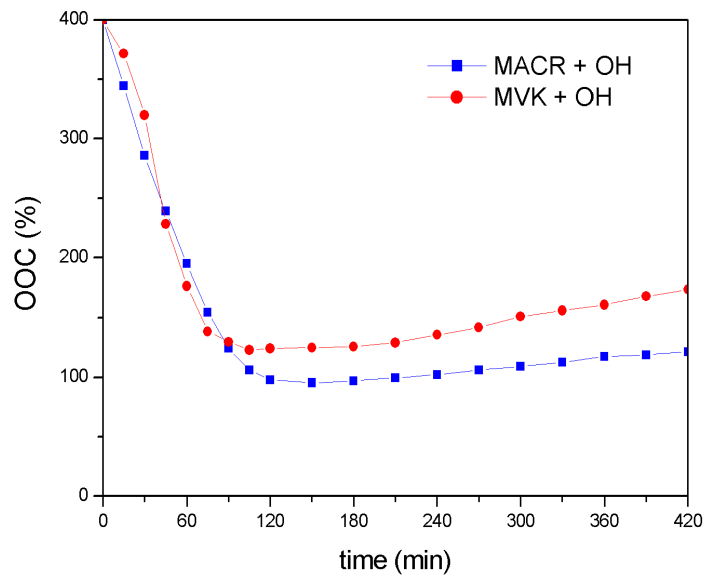

Fig. 8. Total organic carbon balance from the $\mathrm{OH}$-oxidation of MACR and MVK

intermediates are formaldehyde, formic acid and methylglyoxal, while oxalic acid is apparently produced later because its concentration starts to accumulate after MACR is consumed. Acetic acid and pyruvic acid can be regarded as both first and secondary-generation products, since their concentrations are continuously increasing. The yields of formaldehyde, methylglyoxal and acetic acid after $0.2 \mathrm{mM}$ MACR was fully consumed are comparable with results in Liu et al. (2009). When calculating molar yields for the MVK oxidation, we have taken into account the fraction of MVK that transformed to crotonaldehyde, see Fig. 7.

Based on the calculated molar yields, the observed organic carbon (OOC, defined as the sum of dissolved organic carbon molar yields) was estimated here, taking the observed carbonyls and organic acids as the only products present in these two reaction systems (R4). As shown in Fig. 8, the amount of OOC at longer irradiation time is much lower than the initial value, indicating that a significant portion of products were not characterized in this study. These 
missing products primarily possibly include organic peroxides. Moreover, some compounds, like formic acid, will be completely oxidized into $\mathrm{CO}_{2}$ and $\mathrm{H}_{2} \mathrm{O}$, which are difficult to measure in the aqueous phase. In Liu et al. (2009), the total carbon yields were also far from being balanced and they suggested that the non qualified oligomers could explain the lack of carbon. OOC values begin to increase at $3 \mathrm{~h}$ because a substantial amount of organic acids are created. Since firstgeneration intermediates are almost consumed, some reaction routes involving multi-functional compounds might lead to their production. As shown in Fig. 3, most HMWs reach a plateau or begin to decrease after $\sim 3 \mathrm{~h}$ of reaction, shedding light on the possibility that further degradation of HMWs contribute to the organic acid formation.

$\operatorname{OOC}_{\text {MACR }}(\%)=4 \times\left[\mathrm{MACR}_{\text {yield }}\right]+\left[\mathrm{FA}_{\text {yield }}\right]+$

$3 \times\left[\mathrm{MG}_{\text {yield }}\right]+\left[\mathrm{FOA}_{\text {yield }}\right]+2 \times\left[\mathrm{OA}_{\text {yeild }}\right]+3 \times\left[\mathrm{PA}_{\text {yield }}\right]$

$\operatorname{OOC}_{\mathrm{MVK}}(\%)=4 \times\left[\mathrm{MVK}_{\text {yield }}\right]+\left[\mathrm{FA}_{\text {yield }}\right]+$

$2 \times\left[\mathrm{GL}_{\text {yield }}\right]+3 \times\left[\mathrm{MG}_{\text {yield }}\right]+\left[\mathrm{FOA}_{\text {yield }}\right]+2 \times\left[\mathrm{OA}_{\text {yeild }}\right]+$

$3 \times\left[\mathrm{PA}_{\text {yield }}\right]+3 \times\left[\mathrm{MA}_{\text {yield }}\right]$

Both MACR-OH and MVK-OH reactions generate dicarboxylic acids, which are recognized as precursors of SOA. The SOA yield, defined as the ratio of the mass concentration of aerosol formed to that of MACR/MVK reacted, increases significantly with the reaction time. The maximum values are $8.8 \%$ from MACR-OH and 23.8\% from MVK-OH after $7 \mathrm{~h}$ reaction, if the partition efficiency of both oxalic and malonic acid was estimated as $100 \%$. It should be noted that the estimated SOA yield in this study cannot be completely applied to atmospheric clouds conditions, for the following three reasons. (i) The observed HMWs were not considered in the calculation. (ii) All dicarboxylic acids react further with $\mathrm{OH}$ to form smaller acids (Ervens, et al., 2008), resulting in a decrease of the total SOA mass. (iii) SOA production will be interrupted by evapo-condensation cycles, considering that the lifetime of an individual cloud droplet is only a few minutes. However, these SOA formation pathways might continue during water evaporation (El Haddad, et al., 2009).

\subsection{Modeling}

Based on the assumed mechanism and a set of known reaction rate constants, we have conducted a kinetic simulation of these two reaction systems. As shown in Figs. 9 and 10 , the temporal profiles of first-generation intermediates, namely, formaldehyde, glyoxal, methylglyoxal, and formic acid are predicted with reasonable agreement to the experimental data. But the model failed to simulate the kinetics of acetic, pyruvic and oxalic acid. Note that the measured concentrations of acetic and pyruvic acid were still increasing after 3-h reaction, when first-generation intermediates were
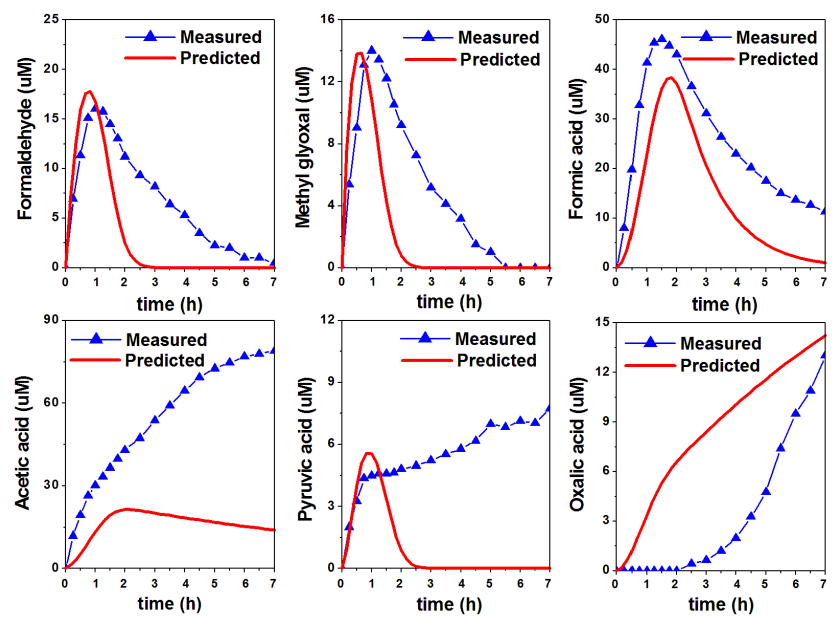

Fig. 9. Measured and predicted concentrations of small products from the MACR-OH reaction.
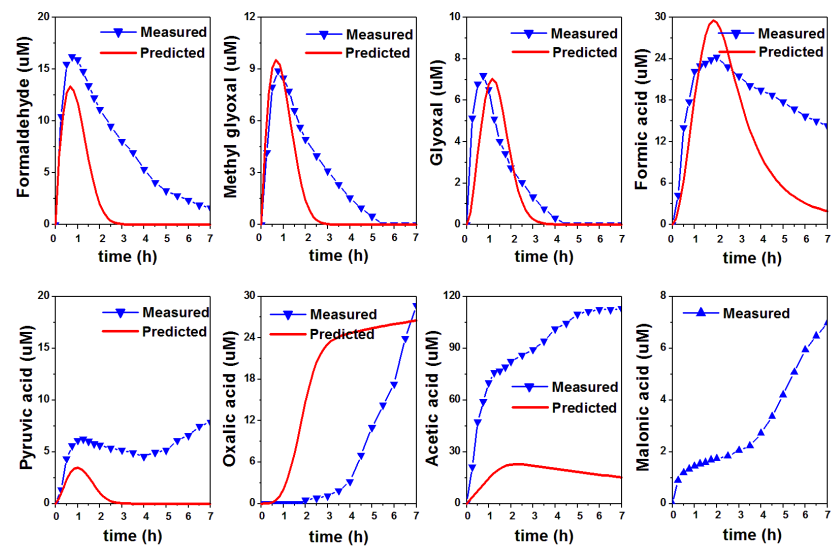

Fig. 10. Measured and predicted concentrations of small products from the MVK-OH reaction.

insufficient to be responsible for their formation. We suggest the decomposition of HMWs probably accounted for the subsequent growth of these organic acids. This hypothesis can be supported by the HPLC-MS analysis of products, see Fig. 3b, showing that HMWs stop growing at longer irradiation time. To the best of our knowledge, Carlton et al. (2007) expanded mechanisms for the aqueous photooxidation of glyoxal by adding simplified reactions of larger multifunctional species and they found these reactions appear to be responsible for most of the oxalic acid production. Thus, detailed mechanisms involving reaction rate constants for specific HMWs are needed to be incorporated in our model for better explaining our observations.

As for oxalic acid, the shape of simulated kinetic curve was not consistent with the observed one, even though the model reproduced its concentrations to more than $85 \%$ in both two reactions. The aqueous mechanism in our box model has offered three channels to the oxalic acid 

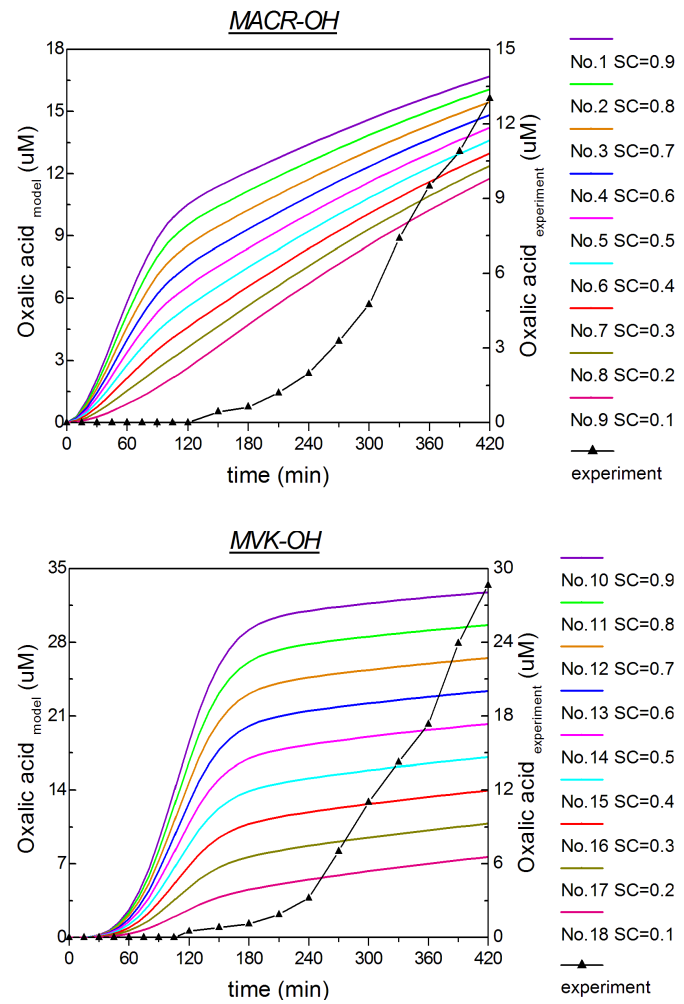

Fig. 11. Evaluation of the effect of stoichiometric coefficients (SC) of glyoxylic acid and glycolaldehyde on the oxalic acid yield (simulation No. 1-9 for MACR-OH and simulation No. 10-18 for MVK$\mathrm{OH})$.

formation. The first one originates from $\mathrm{H}$-atom abstraction of acetic acid by $\mathrm{OH}$, the second starts with glycolaldehyde via either glycolic acid or glyoxal as an intermediate, and the third begins directly from glyoxylic acid. Since the decomposition rate of acetic acid is slow, the last two channels become the major contributor to oxalic acid. To our knowledge, the stoichiometric coefficients for the formation of glycolaldehyde and glyoxylic acid are not known, thus can be treated as adjustable parameters. A sensitivity analysis was undertaken and 18 simulations (No. 1-9 for MACR-OH and No. 10-18 for MVK-OH) were performed under different stoichiometric coefficients, namely, from 0.1 to 0.9 . Figure 11 shows the model responses, represented by oxalic acid concentrations as a function of time. On the one hand, higher stoichiometric coefficients lead to higher oxalic acid yields. One the other hand, the shape of simulated kinetic curves tends to resemble the observed one at lower stoichiometric coefficients. This discrepancy can be ascribed to the competition for $\mathrm{OH}$ radicals between oxalic acid precursors and other reactive species. In this manner, in order to better simulate oxalic acid both in shape and dose, we suggest that the three channels in our model were possibly not the dominating oxalic acid formation pathways and other routes, like the decomposition of HMWs, potentially play an important role in the oxalic acid production. Confirmation of this hypothesis, however, needs corresponding measurement for kinetics of $\mathrm{OH}$-initiated reactions and detailed characterization of HMWs.

\section{Conclusions and implications}

An experimental study of the aqueous $\mathrm{OH}$-oxidation of MACR and MVK at cloud relevant conditions is reported in this work. We propose that the reaction of MACR/MVK with $\mathrm{OH}$ radical is dominated by radical processes giving rise primarily to low-molecular-weight products, including the SOA precursor dicarboxylic acids. Notably, the formation of malonic acid from MVK is unexpected, highlighting the importance of aqueous MVK chemistry in SOA formation. These two reactions also generate HMWs, which contribute SOA upon droplet evaporation. It is interesting to note that MVK will transform, at least in part, to its isomer crotonaldehyde in water phase, increasing the variety of products and complicacy of mechanisms in the real atmosphere. Based on the proposed mechanisms, a box model was used to simulate the kinetics of small products. Model predictions which were in good agreement with experimental observations were first-generation intermediates. However, concentrations of organic acids simulated were much lower than those measured at longer irradiation time, indicating that some additional chemistry might be responsible for the continuous production of organic acids. We also made a sensitivity analysis for the yield of oxalic acid and the simulation results suggests the decomposition of HMWs might contribute significantly to the its formation.

This work adds to the increasing body of literatures that cloud processing contributes to the SOA formation in the atmosphere. In addition, the chemical pathways proposed in this study are mostly applicable to aqueous particles. Considering the higher concentrations of dissolved particle constituents and longer lifetime of aqueous particles (Ervens and Volkamer, 2010), the aqueous MACR/MVK oxidation should play a more important role in atmospheric chemistry than expected before. The SOA mass yield evaluated in this study is supposed to be less than the amount produced in real clouds because we cannot rule out the possibility that pathways involving HMWs account for a significant fraction of SOA in the aqueous phase. Detailed mechanism is still needed so that they can be incorporated into kinetics models to better predict SOA formation from cloud processing.

\section{Supplementary material related to this article is available online at: http://www.atmos-chem-phys.net/10/9551/2010/ acp-10-9551-2010-supplement.pdf.}


Acknowledgements. The authors gratefully thank the National Natural Science Foundation of China (grants 20677002, 40875072, and 21077003) for their financial support, the help from J. L. Li, College of Environmental Sciences and Engineering of Peking University, for model discussions, and the help from D. Huang, the same college, for control experiments.

Edited by: R. Cohen

\section{References}

Altieri, K. E., Carlton, A. G., Turpin, B. J., and Seitzinger, S. P.: Formation of oligomers in cloud processing: reactions of isoprene oxidation products, Environ. Sci. Technol., 40, 4956-4960, 2006.

Altieri, K. E., Seitzinger, S. P., Carlton, A. G., Turpin, B. J., Klein, G. C., and Marshall, A. G.: Oligomers formed through in-cloud methylglyoxal reactions: chemical composition, properties, and mechanisms investigated by ultra-high resolution FT-ICR mass spectrometry, Atmos. Environ., 42, 1476-1490, 2008.

Aschmann, S. M., Arey, J., and Atkinson, R.: OH radical formation from the gas phase reactions of $\mathrm{O}_{3}$ with methacrolein and methyl vinyl ketone, Atmos. Environ., 30, 2939-2943, 1996.

Atkinson, R. and Arey, J.: Atmospheric degradation of volatile organic compounds, Chem. Rev., 103, 4605-4683, 2003.

Barton, S., Morton, F., and Porter, C. R.: Rearrangement of hexamethyl acetone, Nature, 169, 373-374, 1952.

Blando, J. D. and Turpin, B. J.: Secondary organic aerosol formation in cloud and fog droplets: a literature evaluation of plausibility, Atmos. Environ., 34, 1623-1632, 2000.

Carlton, A. G., Lim, H. J., Altieri, K., Seitinger, S., and Turpin, B. J.: Link between isoprene and secondary organic aerosol (SOA): pyruvic acid oxidation yields low volatility organic acids in clouds, Geophys. Res. Lett., 33, L06822, doi:10.1029/2005GL025374, 2006.

Carlton, A. G., Turpin, B. J., Altieri, K. E., Reff, A., Seitzinger, S. P., Lim, H. J., and Ervens, B.: Atmospheric oxalic acid and SOA production from glyoxal: results of aqueous photo oxidation experiments, Atmos. Environ., 41, 7588-7602, 2007.

Carlton, A. G., Turpin, B. J., Altieri, K. E., Reff, A., Seitzinger, S. P., Mathur, R., Roselle, S. J., and Weber, R. J.: CMAQ model performance enhanced when in-cloud secondary organic aerosol is included: comparisons of organic carbon predictions with measurements, Environ. Sci. Technol., 42, 8798-8802, 2008.

Carlton, A. G., Wiedinmyer, C., and Kroll, J. H.: A review of secondary organic aerosol formation from isoprene, Atmos. Chem. Phys., 9, 4987-5005, doi:10.5194/acp-9-4987-2009, 2009.

Chen, J., Griffin, R. J., Grini, A., and Tulet, P.: Modeling secondary organic aerosol formation through cloud processing of organic compounds, Atmos. Chem. Phys., 7, 5343-5355, doi:10.5194/acp-7-5343-2007, 2007.

Chen, Z. M., Jie, C. Y., Li, S., Wang, C. X., Xu, J. R., and Hua, W.: Heterogeneous reactions of methacrolein and methyl vinyl ketone: Kinetics and mechanisms of uptake and ozonolysis on silicon dioxide, J. Geophys. Res., 113, D22303, doi:10.1029/2007JD009754, 2008a.

Chen, Z. M., Wang, H. L., Zhu, L. H., Wang, C. X., Jie, C. Y., and Hua, W.: Aqueous-phase ozonolysis of methacrolein and methyl vinyl ketone: a potentially important source of atmo- spheric aqueous oxidants, Atmos. Chem. Phys., 8, 2255-2265, doi:10.5194/acp-8-2255-2008, 2008b.

Claeys, M., Wang, W., Ion, A. C., Kourtchev, I., Gelencsér, A., and Maenhaut, W.: Formation of secondary organic aerosols from isoprene and its gas-phase oxidation products through reaction with hydrogen peroxide, Atmos. Environ., 38, 4093-4098, 2004.

El Haddad, I. E., Liu, Y., Nieto-Gligorovski, L., Michaud, V., Temime-Roussel, B., Quivet, E., Marchand, N., Sellegri, K., and Monod, A.: In-cloud processes of methacrolein under simulated conditions - Part 2: formation of secondary organic aerosol, Atmos. Chem. Phys., 9, 5107 - 5117, doi:10.5194/acp-9-51072009, 2009.

Ervens, B., Carlton, A. G., Turpin, B. J., Altieri, K. E., Kreidenweis, S. M., and Feingold, G.: Secondary organic aerosol yields from cloud-processing of isoprene oxidation products, Geophys. Res. Lett., 35, L02816, doi:10.1029/2007GL031828, 2008.

Ervens, B. and Volkamer, R.: Glyoxal processing by aerosol multiphase chemistry: towards a kinetic modeling framework of secondary organic aerosol formation in aqueous particles, Atmos. Chem. Phys., 10, 8219-8244, doi:10.5194/acp-10-8219-2010, 2010.

Finlayson-Pitts, B. J. and Pitts, J. N.: Chemistry of the Upper and Lower Atmosphere, Academic Press, New York, USA, 2000.

Gierczak, T., Burkholder, J. B., Talukdar, R. K., Mellouki, A., Barone, S. B., and Ravishankara, A. R.: Atmospheric fate of methyl vinyl ketone and methacrolein, J. Photochem. Photobio. A., 110, 1-10, 1997.

Griffin, R., Cocker, D., Flagan, R., and Seinfeld, J. H.: Organic aerosol formation from the oxidation of biogenic hydrocarbons, J. Geophys. Res., 104, 3555-3567, 1999.

Guzman, M. I., Colussi, A. J., and Hoffmann, M. R.: Photo induced oligomzerization of aqueous pyruvic acid, J. Phys. Chem., A, 110, 3619-3626, 2006.

Henze, D. K. and Seinfeld, J. H.: Global secondary organic aerosol from isoprene oxidation, Geophys. Res. Lett., 33, L09812, doi:10.1029/2006GL025976, 2006.

Herrmann, H., Ervens, B., Jacob, H. W., Wolke, R., Nowacki, P., and Zellner, R.: CAPRAM2.3: A chemical aqueous phase radical mechanism for tropospheric chemistry, J. Atmos. Chem., 36, 231-330, 2000.

Herrmann, H., Tilgner, A., Barzaghi, P., Majdik, Z., Gligorovski, S., Poulain, L., and Monod, A.: Towards a more detailed description of tropospheric aqueous phase organic chemistry: CAPRAM 3.0, Atmos. Environ., 39, 4351-4363, 2005.

Hua, W., Chen, Z. M., Jie, C. Y., Kondo, Y., Hofzumahaus, A., Takegawa, N., Lu, K. D., Miyazaki, Y., Kita, K., Wang, H. L., Zhang, Y. H., and Hu, M.: Atmospheric hydrogen peroxide and organic hydroperoxides during PRIDE-PRD'06, China: their concentration, formation mechanism and contribution to secondary aerosols, Atmos. Chem. Phys., 8, 6755-6773, doi:10.5194/acp-8-6755-2008, 2008.

Iraci, L. T., Baker, B. M., Tyndall, G. S., and Orlando, J. J.: Measurements of the Henry's law coefficients of 2-methyl-3-buten-2ol, methacrolein, and methyl vinyl ketone, J. Atmos. Chem., 33, 321-330, 1999.

Kanakidou, M., Seinfeld, J. H., Pandis, S. N., Barnes, I., Dentener, F. J., Facchini, M. C., Van Dingenen, R., Ervens, B., Nenes, A., Nielsen, C. J., Swietlicki, E., Putaud, J. P., Balkanski, Y., Fuzzi, S., Horth, J., Moortgat, G. K., Winterhalter, R., Myhre, C. E. 
L., Tsigaridis, K., Vignati, E., Stephanou, E. G., and Wilson, J.: Organic aerosol and global climate modeling: a review, Atmos. Chem. Phys., 5, 1053-1123, doi:10.5194/acp-5-1053-2005, 2005

Kroll, J. H., Ng, N. L., Murphy, S. M., Flagan, R. C., and Seinfeld, J. H.: Secondary organic aerosol formation from isoprene photooxidation under high- $\mathrm{NO}_{x}$ conditions, Geophys. Res. Lett., 32, L18808, doi:10.1029/2005GL023637, 2005.

Kroll, J. H., Ng, N. L., Murphy, S. M., Flagan, R. C., and Seinfeld, J. H.: Secondary organic aerosol formation from isoprene photooxidation, Environ. Sci. Technol., 40, 1869-1877, 2006.

Lim, H. J., Carlton, A. G., and Turpin, B. J.: Isoprene forms secondary organic aerosol through cloud processing: model simulations, Environ. Sci. Technol., 39, 4441-4446, 2005.

Liu, Y., El Haddad, I., Scarfogliero, M., Nieto-Gligorovski, L., Temime-Roussel, B., Quivet, E., Marchand, N., PicquetVarrault, B., and Monod, A.: In-cloud processes of methacrolein under simulated conditions - part 1: aqueous phase photooxidation, Atmos. Chem. Phys., 9, 5093-5105, doi:10.5194/acp-95093-2009, 2009.

Montzka, S. A., Trainer, M., Goldan, P. D., Kuster, W. C., and Fehsenfeld, F. C.: Isoprene and its oxidation-products, methyl vinyl ketone and methacrolein, in the rural troposphere, J. Geophys. Res., 98, 1101-1111, 1993.

Ng, N. L., Kroll, J. H., Keywood, M. D., Bahreini, R., Varutbangkul, V., Flagan, R. C., Seinfeld, J. H., Lee, A., and Goldstein, A. H.: Contributions of first-versus second-generation products to secondary organic aerosols formed in the oxidation of biogenic hydrocarbons, Environ. Sci. Technol., 40, 2283-2297, 2006.

Nozière, B., Voisin, D., Longfellow, C. A., Friedli, H., Henry, B. E., and Hanson, D. R.: the uptake of methyl vinyl ketone, methacrolein, and 2-methyl-3-butene-2-ol onto sulfuric acid solutions, J. Phys. Chem., A, 110, 2387-2395, 2006.

Nozière, B., Ekström, S., Alsberg, T., and Holmström, S.: Radical-initiated formation of organosulfates and surfactants in atmospheric aerosols, Geophys. Res. Lett., 37, L05806, doi:10.1029/2009GL041863, 2010.

Orlando, J. J., Tyndall, G., S., and Paulson, S. E.: Mechanism of the $\mathrm{OH}$-initiated oxidation of methacrolein, Geophys. Res. Lett., 26, 2191-2194, 1999.

Perri, M. J., Seitzinger, S. P., and Turpin, B. J.: Secondary organic aerosol production from aqueous photooxidation of glycolaldehyde: laboratory experiments, Atmos. Environ., 43, 1487-1497, 2009.

Perri, M. J., Lim, Y. B., Seitzinger, S. P., and Turpin, B. J.: Organosulfates from glycolaldehyde in aqueous aerosols and clouds: laboratory studies, Atmos. Environ., 44, 2658-2664, 2010.

Rothrock, T. S. and Fry, A.: A carbon-14 tracer study of the acidcatalyzed rearrangement of 3,3-dimethyl-2-butanone-1- $\mathrm{C}^{14}$, J. Am. Chem. Soc., 80, 4349-4354, 1958.

Simpson, D., Winiwarter, W., Borjesson, G., Cinderby, S., Ferreiro, A., Guenther, A., Hewitt, C. N., Janson, R., Khalil, M. A. K., Owen, S., Pierce, T. E., Puxbaum, H., Shearer, M., Skiba, U., Steinbrecher, R., Tarrason, L., and Oquist, M. G.: Inventorying emissions from nature in Europe, J. Geophys. Res., 104, 81138152,1999
Sorooshian, A., Lu, M. L., Brechtel, F. J., Jonsson, H., Feingold, G., Flagan, R., C., and Seinfeld, H. J.: On the source of organic acid aerosol layers above clouds, Environ. Sci. Technol., 41, 46474654, 2007.

Stefan, M. I., Hoy, A. R., and Bolton, J. R.: Kinetics and mechanism of the degradation and mineralization of acetone in dilute aqueous solution sensitized by the UV photolysis of hydrogen peroxide, Environ. Sci. Technol., 30, 2382-2390, 1996.

Surratt, J. D., Murphy, S. M., Kroll, J. H., Ng, N. L., Hildebrant, L., Sorooshian, A., Szmigielski, R., Vermeylen, R., Maenhaut, W., Claeys, M., Flagan, R. C., and Seinfeld, J. H.: Chemical composition of secondary organic aerosol formed from photooxidation of isoprene, J. Phys. Chem. A, 110, 9665-9690, 2006.

Szmigielski, R., Surratt, J. D., Vermeylen, R., Szmigielska, K., Kroll, J. H., Ng, N. L., Murphy, S. M., Sorooshian, A., Seinfeld, J. H., and Claeys, M.: Characterization of 2-methylglyceric acid oligomers in secondary organic aerosol formed from the photooxidation of isoprene using trimethylsilylation and gas chromatography/ion trap mass spectrometry, J. Mass Spectrom., 42(1), 101-116, 2007.

Tan, Y., Perri, M. J., Seitzinger, S. P., and Turpin, B. J.: Effects of precursor concentration and acidic sulfate in aqueous glyoxal$\mathrm{OH}$ radical oxidation and implications for secondary organic aerosol, Environ. Sci. Technol., 43, 8105-8112, 2009.

Tuazon, E. C. and Atkinson, R.: A product study of the gas-phase reaction of methyl vinyl ketone with the $\mathrm{OH}$ radical in the presence of $\mathrm{NO}_{\mathrm{x}}$, Int. J. Chem. Kinet., 21, 1141-1152, 1989.

Tuazon, E. C. and Atkinson, R.: A product study of the gas-phase reaction of methacrolein with the $\mathrm{OH}$ radical in the presence of $\mathrm{NO}_{x}$, Int. J. Chem. Kinet., 22, 591-602, 1990.

van Pinxteren, D., Plewka, A., Hofmann, D., Muller, K., Kramberger, H., Svrcina, B., Bächmann, K., Jaeschke, W., Mertes, S., Collett Jr., J. L., and Herrmann, H.: Schmucke hill cap cloud and valley stations aerosol characterization during FEBUKO (II): Organic compounds, Atmos. Environ., 39, 4305-4320, 2005.

Volkamer, R., Ziemann, P. J., and Molina, M. J.: Secondary organic aerosol formation from acetylene $\left(\mathrm{C}_{2} \mathrm{H}_{2}\right)$ : seed effect on SOA yields due to organic photochemistry in the aerosol aqueous phase, Atmos. Chem. Phys., 9, 1907-1928, doi:10.5194/acp9-1907-2009, 2009.

von Sonntag, C. and Schuchman, H.-P.: Peroxyl radicals in aqueous solutions, John Wiley \& Sons, New York, USA, 1997.

Wang, H. L., Zhang, X., and Chen, Z. M.: Development of DNPH/HPLC method for the measurement of carbonyl compounds in the aqueous phase: applications to laboratory simulation and field measurement, Environ. Chem., 6, 389-397, 2009.

Warneck, P.: Chemistry of the natural atmosphere, 2nd edition, Acedemic Press, San Diego, CA, USA, 2000.

Zhang, X., Chen, Z. M., Wang, H. L., He, S. Z., and Huang, D. M.: An important pathway for ozonolysis of alpha-pinene and betapinene in aqueous phase and its implications, Atmos. Environ., 43, 4465-4471, 2009.

Zhao, Y., Chen, Z. M., and Zhao, J. N.: Heterogeneous reactions of methacrolein and methyl vinyl ketone on $\alpha-\mathrm{Al}_{2} \mathrm{O}_{3}$ particles, Environ. Sci. Technol., 44, 2035-2041, 2010.

Zook, H. D. and Paviak, S. C.: Fission of t-butyl alkyl ketones in the schmidt reaction, J. Am. Chem. Soc., 77, 2501-2503, 1955. 